\title{
IMPROVING DISASTER RESPONSE PROCESSES USING KEYWORDS SPECIFICALLY FOR EARTHQUAKES
}

\author{
JAEHWANG AHN ${ }^{1}$, YUONGJE CHOI ${ }^{1}$, BYUNGSIK KIM $^{2}$ \& JAEEUNG YI ${ }^{1}$ \\ ${ }^{1}$ Department of Civil and Transportation Engineering, Ajou University, South Korea \\ ${ }^{2}$ Department of Climate Change, Urban and Environmental Disaster Research Laboratory, \\ Kangwon National University, South Korea
}

\begin{abstract}
As Korean society has become more advanced, recent disasters have become more complex, especially when they occur simultaneously with natural disasters. As part of the efforts to cope effectively with a diverse range of disasters, the efficiency of disaster response operations has been reconsidered and ways to improve existing disaster management processes have been investigated. Currently, disaster operations in South Korea are carried out in accordance with type-specific disaster manuals. Although disaster management based on manuals can guarantee clarity and legitimacy, limitations include poor reporting and feedback during disaster operations, difficulty disseminating disaster information, and ineffective training in disaster prevention and preparedness. To overcome these limitations, this study sought to effectively improve disaster services by synthesizing disaster information, which has become much more detailed and accessible due to the development of information technology, with disaster management processes. The research process was as follows: (1) Collect disaster-related keywords for earthquakes in Korea, which have recently become an issue; (2) Evaluate the suitability of the collected disaster-related keywords by conducting a survey of individuals in charge of disaster operations and those in charge of disaster information; (3) Use the results of the survey to associate the disaster-related keywords with the individual disaster management stages; (4) Develop a disaster operation process based on a keyword matrix; and (5) Present a disaster support system model that can effectively express the link between the disaster management stages and disaster-related keywords. This system enables those in charge of disaster response operations to construct a system model for disaster service support that effectively accesses disaster-related keywords that are collected and analysed based on various disaster service characteristics.
\end{abstract}

Keywords: disaster management, South Korea, disaster-related keyword, earthquake, keyword matrix, disaster support system.

\section{INTRODUCTION}

\subsection{Background}

In order to effectively respond to large-scale and complex disasters, a number of studies have been carried out to enhance the efficiency of existing disaster management processes to enable rapid disaster responses [1]-[3]. There are generally four stages in disaster management - prevention, preparation, response, and recovery [4] - and South Korea disaster management operates according to manuals created for each of these stages. However, disaster management based on pre-printed manuals is limited in terms of reporting and feedback on disaster responses, disseminating information about disasters, and providing education for disaster prevention and preparedness [5], [6]. In particular, the amount of disaster-related information available in Korea has increased dramatically compared to the past, but its utilization rate is not high. The reason for this is the passive disaster management structure in which disaster information is collected individually for each issue based on the judgment of the person in charge of the disaster services when a disaster occurs [7]. To 
overcome these problems, developing a disaster information support system that provides accurate, customized disaster information for various disaster services is necessary.

\subsection{Research scope}

In this paper, earthquakes were selected as the focal disaster type because they have recently become a major issue in South Korea. In addition, the classification of disaster information was performed individually between information of similar significance when all types of information considered were as collectable as possible and when it was difficult to derive the meaning of the analysis results. For this reason, this study was conducted based on disasterrelated keywords to indicate the representative nature of similar disaster information.

\subsection{Related research}

Efforts to analyse the link between disaster operations and disaster information while providing customized information for each management stage has actively been studied both domestically and abroad. International research has investigated and defined current knowledge management systems and disaster analysis processes related to disasters [7]. Specifically, studies have focused on improving disaster management systems by designing a disaster situation browser system powered by web-based and mobile devices. In addition, other research has analysed the use of big data in disaster operations [8], [9].

In domestic research, previous studies have analysed Korea's current system and laws for disaster management and have offered suggestions for the direction the nation should move in based on the experiences of other advanced countries. In particular, past studies have focused on improving the mutual support system for disaster management organizations, strengthening the response of local governments to disasters, readjusting laws and organizational systems to clarify the procedures and responsibilities of disaster management institutions, integrating disaster management systems, expanding personnel, preparing a database for resource management, establishing an integrated national disaster communication system, readjusting the delivery system for disaster situations, and strengthening social disaster response capabilities [10]. In addition, research has been carried out to derive disaster information that is consistent with the needs of users by analysing domestic and foreign disaster management information systems and surveying system users. Other studies include a quantitative assessment of disaster policy priorities at each stage of work that should be considered in a disaster management system [11]. An Analytic Hierarchy Process (AHP) assessment of the disaster management stages and the activities within each stage relevant to the disaster management system has also been conducted [12].

\section{RESEARCH METHODS}

The objective of this research was to enable individuals in charge of disaster operations to actively perform their duties by making use of disaster-related keywords in disaster operations. To achieve this, a disaster response stage-disaster keyword matrix was developed to link the disaster management stages with disaster-related keywords. In addition, realistic measures were developed to support disaster operations by presenting the results of the connection between disaster operation processes and the keywords in the disaster information system.

The present study was conducted in four stages: (1) eliciting essential disaster-related keywords; (2) surveying disaster response personnel to assess the importance of these keywords; (3) determining the priority for the keywords; and (4) improving the process for 
disaster services using the disaster-related keywords. These steps are described in more detail below:

Step 1: In order to collect disaster-related keywords related to earthquakes, the history of past earthquakes was first analysed, followed by an investigation into Google [13] and Naver [14] trends. Interviews with disaster management officials and experts were then conducted.

Step 2: The multiple-choice "Survey for the Assessment of the Importance of Disaster Keywords" was designed to determine the importance of the disaster-related keywords in relation to the individual disaster management stages. The survey participants were either involved in disaster management in some capacity (i.e., public servants and employees at disaster-related agencies) or information recipients (e.g., ordinary citizens). Survey participants were asked to determine the importance of the keywords by weighing them based on their association with the relevant disaster service.

Step 3: The priority of the disaster-related keywords was determined using the survey results. This analysis compared the results of the priority assessment for those involved in disaster operations and those involved in information services.

Step 4: Disaster operations processes were improved using the keywords. In each disaster recovery, the assessment results for the importance of the disaster-related keywords were utilized to derive a plan for providing disaster information through the connection between the disaster response stage-disaster keyword matrix and the disaster keyword-disaster operations relationship.

\section{ESSENTIAL DISASTER-RELATED KEYWORDS}

\subsection{Determining required disaster-related keywords by analysing past disasters}

Information on past disasters was used to derive keywords. The history of about 1,000 accidents from 1997 to 2015 was gathered from a 2016 survey conducted by the Korea Institute for Disaster Safety. The historical accounts consisted of information such as the date, type, region, cause, countermeasures, and recovery measures. The causes of the disaster and countermeasures were analysed in relative detail and used to generate disaster-related keywords.

\subsection{Determining required disaster-related keywords using trend analysis}

The analysis tools provided by the search platforms Naver and Google were used to collect disaster information keywords and analyse the relationship between these keywords and disaster operations. Google Trend Analysis Tool provides user-defined search by region and category and provides a function to analyse comparison searches between search words, related topics and related search terms. Naver Trend Analysis Tool can analyse associations between up to 20 search words by subject language and provides user-defined searches by gender and age. In addition, public data in Korea can be checked simultaneously with related search keywords. In this study, the necessary disaster keywords were derived using two trend analysis tools and the associated keywords related to earthquakes were collected extensively by applying different analysis tools to the same search term. 


\subsection{Determining required disaster-related keywords from expert interviews}

In order to derive disaster-related keywords that can be utilized in actual operations, it was essential to garner the opinions of disaster management personnel and disaster-related experts, who are likely to employ the research results. Because the research was conducted on earthquakes, interviews with individuals in charge of earthquake-related disaster management in Ulsan, South Korea, were conducted. This area has a history of earthquake damage. In addition, through interviews with disaster experts with a history of working in the central disaster situation room, it was possible to identify the essential disaster information keywords that are required for each operational stage.

\subsection{Determining essential disaster-related keywords for each disaster stage}

In order to collect all of the essential disaster-related keywords, analysis of the past history, trend analysis, and interviews with management personnel were carried out. Table 1 presents the essential disaster-related keywords derived for each disaster stage. Keywords collected in common and additional keywords collected in each stage were identified during all stages of disaster response.

\section{A SURVEY TO ASSESS THE IMPORTANCE OF THE DISASTER-RELATED KEYWORDS}

The purpose of the survey was to determine the priority order of the disaster-related keywords for disaster operations. A measure could then be proposed to selectively utilize these keywords based on the ranking of the keywords based on importance and usability.

\subsection{Selection of survey participants}

The survey respondents were divided into those involved in disaster operations who will use the keywords and those who receive disaster information and attempt to understand disaster situations. Those involved in disaster management included local governments, researchers at state-run think tanks related to disasters, public companies related to disasters (e.g., water resources, construction, farming, and fishing), and disaster system designers. The information recipients included members of the disaster-related academic community and the general public.

\subsection{Survey method}

The questionnaire was structured as follows. First, the respondents were asked to give their jobs or relationship to disaster management in order to distinguish between those involved in disaster management and those involved in disaster information. Second, the survey was conducted in the form of a multiple-choice grid to analyse the importance of the disasterrelated keywords for disaster operations. The importance of each keyword was scored by the respondents as very important (5), important (4), normal (3), low importance (2), very low importance (1), or unrelated (0). The survey also included a question asking the participants for their opinions regarding important disaster keywords that should be considered that were not included in the survey.

\section{DISASTER KEYWORD PRIORITY}

The ranked importance of the disaster keywords was determined for each disaster management stage. The assessment results for those involved in the disaster were compared 


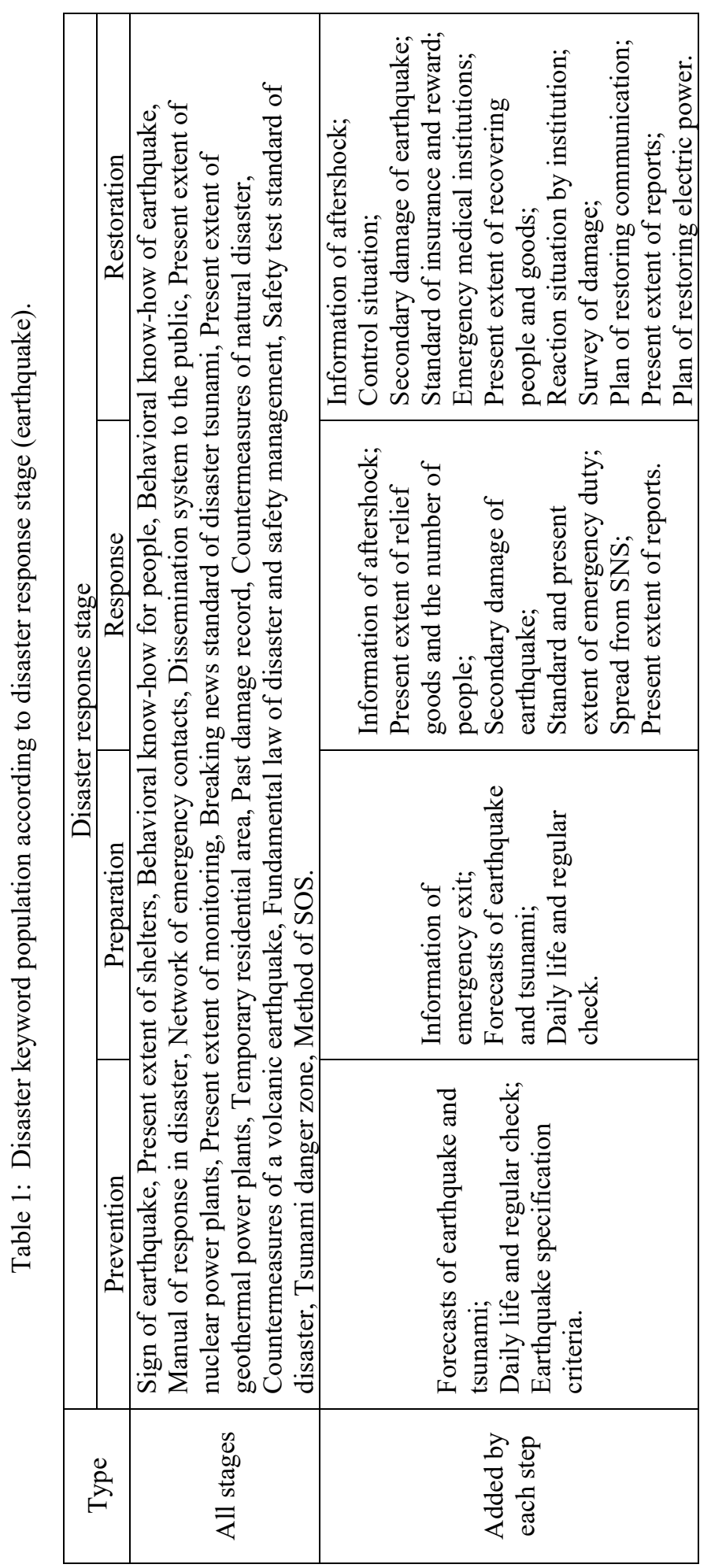


with those related to disaster information services, and differences were weighed based on the relevance of the respondents' jobs. The scores from public officials carried the greatest weight (1.5), followed by disaster-related workers (1.2) and general citizens ( 0.8$)$. The reason for the differential application of the weights is that the group to be used is limited to those responsible for disaster activities, so the assessment of the importance of each local government and the relevant personnel for disaster activities was prioritized. The results of the priority calculation showed that the common requirements for disaster keywords (e.g., disaster response manuals) were generally high in all stages of disaster response, and that disaster keywords, which showed high priority in the survey of those involved in disaster activities, such as the status of reporting and evacuation site status, seismic behavior, and emergency contact networks, were predominantly of high importance.

The total number of people surveyed was 78 , with 48 people involved in disaster operations and 30 people related to disaster information. Tables 2 and 3 present the keywords with the greatest importance for each stage of disaster management: prevention, preparation, response, and recovery.

\section{IMPROVING DISASTER MANAGEMENT PROCESSES}

\subsection{Disaster management stage-disaster keyword matrix}

Currently, Korea's disaster management personnel face difficulties in carrying out active operations due to problems collecting and investigating the information necessary to perform their tasks, the narrow range of information available, and the difficulty in specifying the information necessary for disaster services. However, if a disaster management stagedisaster-related keyword matrix is utilized, each disaster response stage can be quickly associated with the required disaster-related keywords to quickly identify the useful information. The provision of essential information can increase the effectiveness of task processes by allowing daily reports to be prepared for disaster management personnel and disseminating disaster information to the public. As such, a matrix was constructed based on the results of the survey analysis and the results are presented in Table 4.

The disaster response phase-disaster keyword matrix was created in the form of an intuitive check of what disaster information is that can help carry out disaster operations by placing disaster keywords on the vertical axis and placing each disaster response stage on the horizontal axis.

The disaster keywords applied to the matrix were all required disaster keywords collected through past disaster history, trend analysis, disaster task personnel and expert interviews.

The items of disaster keywords, which are the vertical axis of the disaster task-disaster keyword matrix, are keywords that are rated higher in each stage of disaster response as they are located at the top based on the importance calculated by the survey evaluation.

This structure is different from the results of the priority analysis among the aforementioned disaster keywords.

This is because the matrix was constructed in such a way that the disaster response stage, the disaster keyword, and the three-parameter information of importance were presented in a two-dimensional table structure, so that the comprehensive disaster response phase was considered and placed at the top.

As a result, a total of 12 disaster keywords, including the present extent of shelters, sign of earthquake, behavioral know-how for people, behavioral know-how of earthquake, manual of response in disaster, dissemination system to the public, present extent of nuclear power 


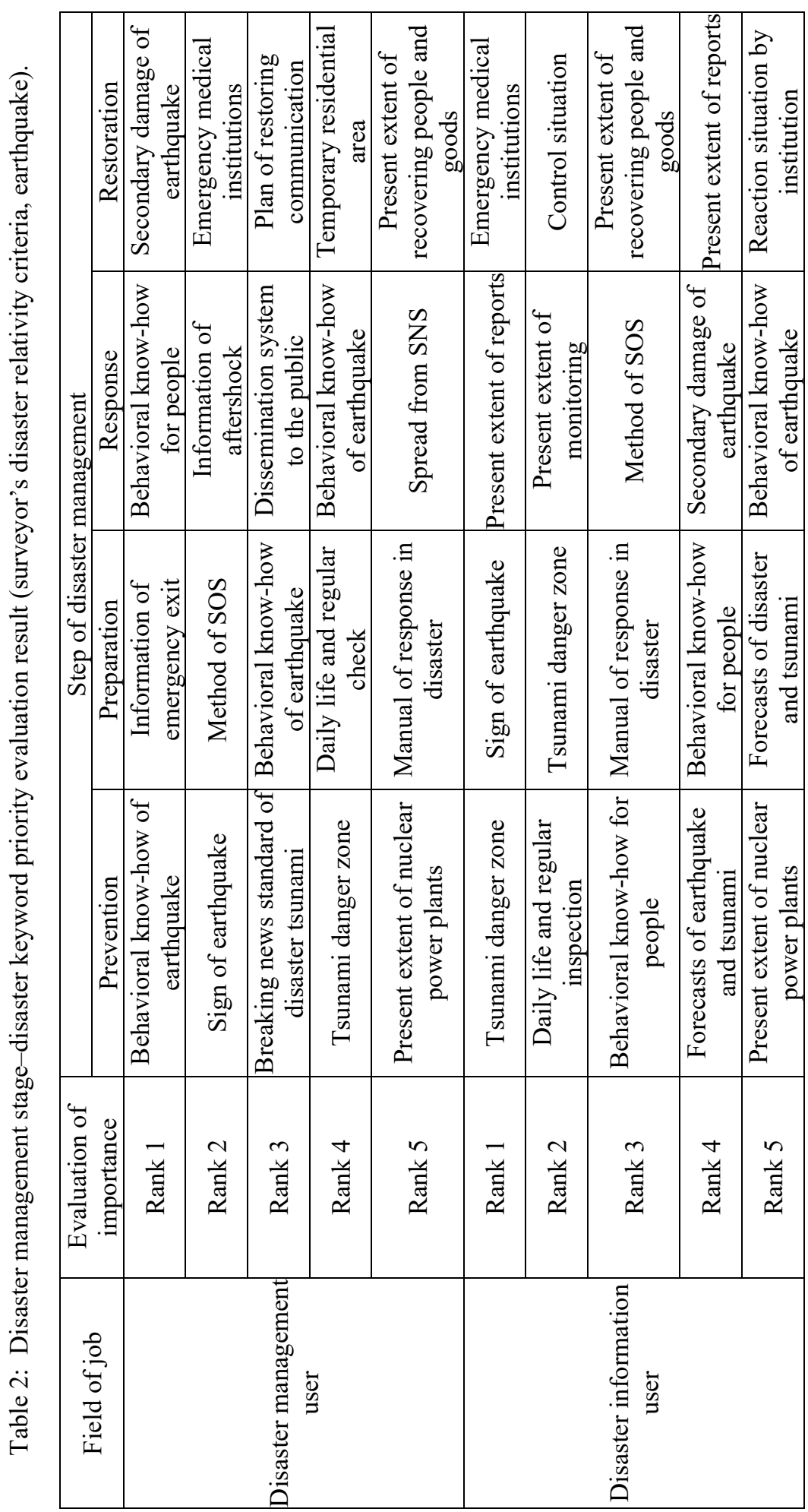




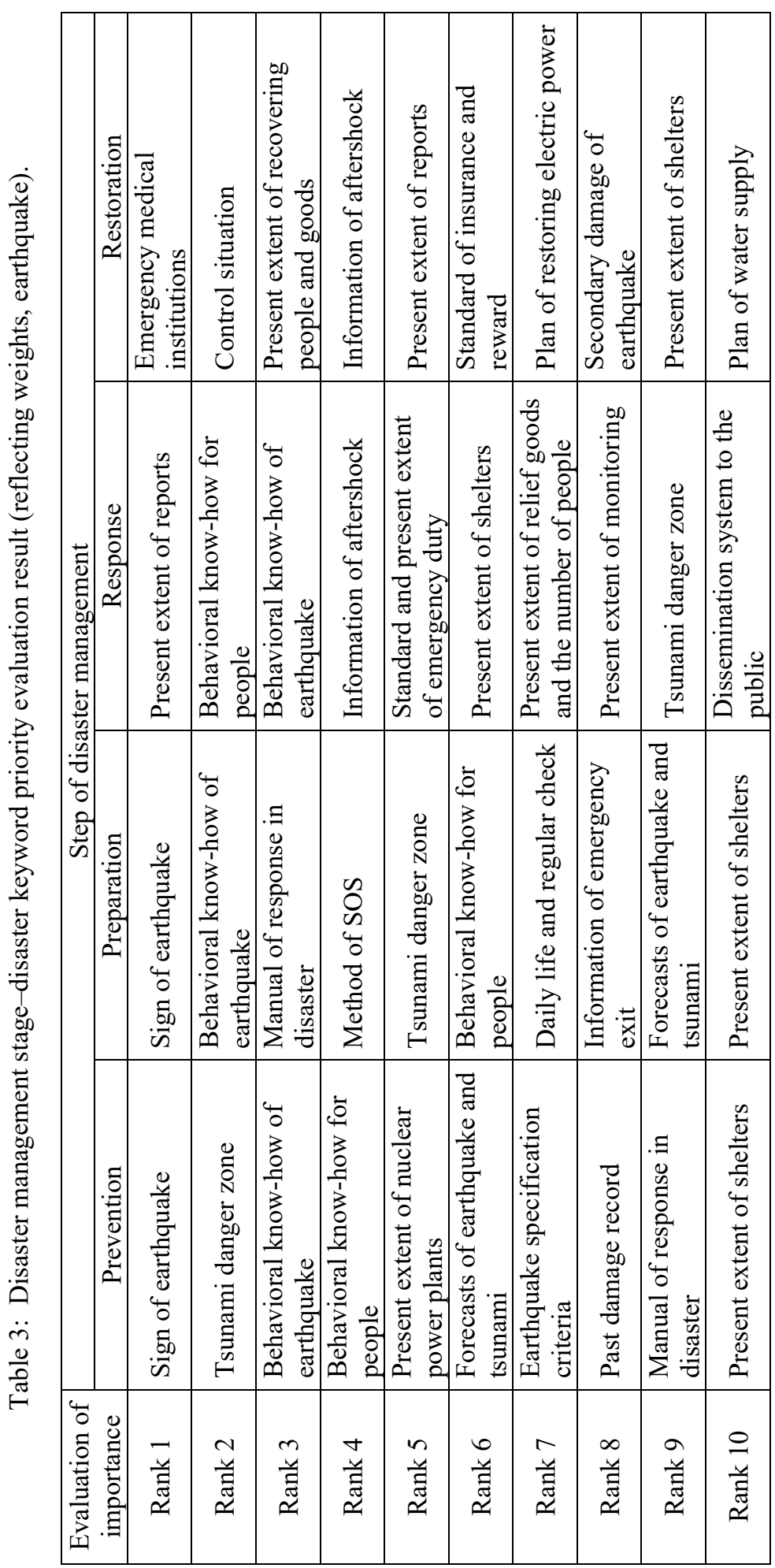


Table 4: Matrix of disaster management stage-disaster keyword (earthquake).

\begin{tabular}{|c|c|c|c|c|}
\hline Division & Prevention & Preparation & Response & Restoration \\
\hline Present extent of shelters & o & o & ○ & o \\
\hline Sign of earthquake & o & o & o & o \\
\hline Behavioral know-how for people & o & o & ○ & o \\
\hline $\begin{array}{l}\text { Behavioral know-how of } \\
\text { earthquake }\end{array}$ & ○ & ○ & $\circ$ & ○ \\
\hline Manual of response in disaster & o & o & o & o \\
\hline Dissemination system to the public & o & 0 & 0 & O \\
\hline $\begin{array}{l}\text { Present extent of nuclear power } \\
\text { plants }\end{array}$ & o & o & ○ & o \\
\hline Present extent of monitoring & O & o & 0 & O \\
\hline $\begin{array}{l}\text { Breaking news standard of disaster } \\
\text { tsunami }\end{array}$ & o & o & ○ & ○ \\
\hline Tsunami danger zone & 0 & o & 0 & 0 \\
\hline Temporary residential area & o & o & o & o \\
\hline Past damage record & ○ & o & o & o \\
\hline Present extent of reports & & o & o & o \\
\hline Method of SOS & & 0 & $\circ$ & ○ \\
\hline Information of emergency exit & & 0 & 0 & 0 \\
\hline Information of aftershock & & & 0 & 0 \\
\hline Control situation & & & $\circ$ & o \\
\hline $\begin{array}{l}\text { Present extent of relief goods and } \\
\text { the number of people }\end{array}$ & & & ○ & ○ \\
\hline Secondary damage of earthquake & & & o & o \\
\hline Standard of insurance and reward & & & & o \\
\hline $\begin{array}{l}\text { Standard and present extent of } \\
\text { emergency duty }\end{array}$ & & & $\circ$ & ○ \\
\hline Spread from SNS & & & ○ & ○ \\
\hline $\begin{array}{l}\text { Forecasts of earthquake and } \\
\text { tsunami }\end{array}$ & o & ○ & & \\
\hline Daily life and regular check & O & 0 & & \\
\hline Emergency medical institutions & & & ○ & ○ \\
\hline $\begin{array}{l}\text { Present extent of recovering people } \\
\text { and goods }\end{array}$ & & & & ○ \\
\hline Reaction situation by institution & & & & o \\
\hline
\end{tabular}

plants, present extent of monitoring, breaking news standard of disaster tsunami, tsunami danger zone, temporary residential area, past damage record, showed the highest importance.

Since disaster information, which is represented by such disaster keywords, is essential in all stages of disaster response, it is expected that the government will be able to provide upto-date information to earthquake-related disaster workers at all times. 
6.2 Improving disaster management using disaster-related keywords

Disaster management is generally divided into prevention, preparation, response, and recovery. This is the standard set by local governments and the central government for the sequential deployment of disaster services based on the manual. Based on the time of the disaster, preventive projects (e.g., the maintenance of disaster prevention facilities) and special district management (e.g., the selection of risk zones and disaster insurance projects) are carried out in the prevention stage. Disaster preparation (e.g., disaster preparedness training and public relations activities for residents) and disaster management personnel education (e.g., strengthening the training and cooperation systems among disaster officials) are required in the preparation stage. In the post-disaster response stage, symptom detection (e.g., signal reception and indication transmission), the initial response (e.g., the situation and response measures), and the emergency response (e.g., operation of the disaster situation room and response measures) are carried out. Finally, in the recovery stage, corresponding and follow-up measures, damage investigation, and cause analysis (e.g., the formation of a cooperative investigation team, relief, and support) are required [15], [16].

The connection between various disaster services and customized disaster keywords can help the associated personnel to collect and judge information intuitively to enable a rapid response. The relationship between the disaster services and disaster-related keywords was established based on the results of the trend analysis, survey, and expert interviews. Fig. 1 displays the link between the disaster management process and the disaster keywords.

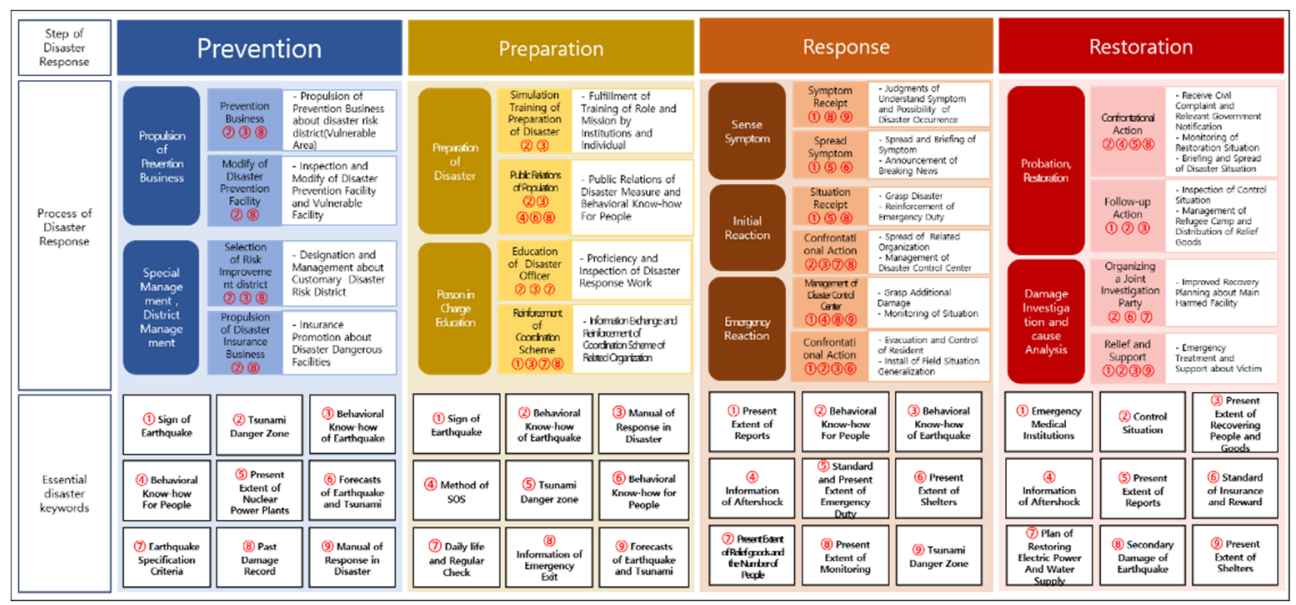

Figure 1: Disaster management process: Essential disaster keyword matching matrix.

\section{CONCLUSION}

The purpose of this study was to improve the existing disaster operation process, to support efficient disaster management by supporting those in charge of disaster operations, and to effectively provide necessary disaster-related keywords for each disaster service. Research has shown that measures to effectively express service and disaster information in the disaster response stage can lead to increased overall effectiveness. The disaster information matrix and the disaster information system can be used by linking the disaster response stages with the keywords; this can be an established measure to support disaster operations. 
The results of the study can be summarized as follows:

1. The importance of disaster-related keywords was assessed by analysing the results of a survey of disaster management personnel and those who receive disaster management information. The priority of the keywords was determined by weighing the survey participants based on their association with the disaster management process. The importance of the keywords as determined by those involved in disaster operations and those receiving information was also compared.

2. As a result of the assessment of importance, those involved in disaster management evaluated keywords related to the collecting of disaster information for reporting and response plans. However, the information recipients prioritized information that was actually helpful to the individuals responding to disaster situations.

3. The disaster-related keywords included in all disaster management stages were seismic action guidelines, past damage history, national action guidelines, seismic hazard prevention measures, basic laws for disaster and safety management, disaster prevention measures, earthquake and tsunami special notification standards, national residential areas, emergency access networks, seismic safety diagnosis standards, and geothermal and nuclear power plants. These keywords represent information used in disaster operations and should always be kept up-to-date in the pre-disaster stage.

4. Based on results of the assessment of importance of the disaster keywords for each disaster management stage, keywords for preventative education and disaster response methods, such as tsunami-risk areas, seismic action instructions, national action guidelines, nuclear power plant status, earthquake and tsunami forecast data, special notification criteria, and shelter status, were of high importance in the prevention and preparation stages. In the response stage, the priority keywords were related to actual disaster situations such as reporting and reporting status, emergency service standards, relief supplies and personnel status, monitoring status, and public dissemination systems. In the recovery stage, control situations, recovery personnel and supplies, insurance and compensation criteria, power recovery plans, and water supply plans were the main keywords.

5. A model for a disaster management stage-disaster-related keyword matrix and the disaster-related keyword-disaster service relationship was implemented using the assessment results, trend analysis, and expert interviews for the keywords by disaster management stage.

6. The results of this research are planned to be used to design a service model for providing disaster information under a "disaster support system" (tentative name), which is currently being implemented by the South Korean government to support local governments and central disaster services. After its implementation, the system will be improved through user-satisfaction analysis.

\section{ACKNOWLEDGEMENT}

This research was supported by a grant (2017-MPSS31-004) from "Supporting Technology Development Program for Disaster Management" funded by the Ministry of the Interior and Safety (MOIS), South Korea. 


\section{REFERENCES}

[1] KICT, Development of scenario-based large-scale complex disaster prediction and evaluation system. Ministry of Science, ICT and Future Planning, 2016.

[2] Song, C.Y. \& Park, S.H., Strategy for improvement of disaster response system of hybrid disaster in Korea. Journal of Korea Institute for Structural Maintenance and Inspection, 21(3), pp. 45-65, 2017.

[3] Heo, J.Y., Extraction of large-scale disaster scenarios and preparation of advance response system. Korea Institute of Public Administration, pp. 6-8, 2012.

[4] Zimmerman, R., The relationship of emergency management to governmental policies on man-made technological disasters. Public Administration Review, 45, pp. 29-39, 1985.

[5] Ryu, C., Disaster Management, 2nd edn., Hansung Culture: Seoul, 2005.

[6] Yoo, I.S., Disaster planning in Korea. Hanyang Medical Reviews, 35(3), pp. 157-173, 2015.

[7] Hristidis, V., Chen, S.-C., Li, T., Luis, S. \& Deng, Y., Survey of data management and analysis in disaster situations. Journal of Systems and Software, 83(10), pp. 1701$1714,2010$.

[8] Zheng, L., Shen, C., Tang, L., Zeng, C., Li, T., Luis, S. \& Chen, S.-C., Data mining meets the needs of disaster information management. IEEE Transactions on HumanMachine Systems, 43(5), 2013.

[9] Joseph, J.K., Akhil Dev, K., Pradeepkumar, A.P. \& Mohan, M., Big data analytics and social media in disaster management. Integrating Disaster Science and Management: Global Case Studies in Mitigation and Recovery, eds P. Samui, D. Kim \& C. Ghosh, Elsevier, 584 pp., 2018.

[10] National Disaster Management Research Institute of Korea, Development of Decision Support Technology for Disaster Management, 2014.

[11] Kim, J.-D., An analysis on the order of priority in disaster management policy. Journal of the Korean Society of Hazard Mitigation, 10(2), pp. 61-68, 2010.

[12] Ko, I.J., Ko, T.H. \& Kang, Y.H., A study on the priority of disaster management system - with emphasis on Jeju special self-governing province. Crisisonomy, 7(4), pp. 1-22, 2011.

[13] Google Trends, www.trends.google.co.kr.

[14] Naver Datalab, www.datalab.naver.com.

[15] Government of the Republic of Korea, Regulations on Crisis, Disaster and Safety Management, Ministry of Environment Directive, No. 1180, 2015.

[16] Government of the Republic of Korea, Regulations for Operation of the General Situation Room for Crisis, Disaster and Safety Management, Ministry of TradeIndustry and Energy Directive, No. 2018-66, 2018. 